\title{
A Case Report on Post-Transplant Erythrocytosis
}

\author{
Khoda MME ${ }^{\mathrm{a}}$, Shimu $\mathrm{IJ}^{\mathrm{b}}$, Hossain $\mathrm{MG}^{\mathrm{c}}$, Haque MS ${ }^{\mathrm{d}}$, Akhtar ${ }^{\mathrm{d}}$, Rahim MA ${ }^{\mathrm{e}}$, Mansur MA ${ }^{\mathrm{f}}$
}

\begin{abstract}
Post-transplant erythrocytosis is defined as persistently elevated haemoglobin and haematocrit levels that occur following renal transplantation and persist for more than six months in the absence of thrombocytosis, leukocytosis or other potential causes of erythrocytosis. Here, we report the case history of a 35-year-old male, who underwent live related kidney transplantation ten months ago, presented with high haemoglobin level and high haematocrit. It is an uncommon complication of kidney transplant recipient, whichprompted us to report the case.
\end{abstract}

Key words: Post-transplant erythrocytosis, live related kidney transplant.

(BIRDEM Med J 2019; 9(2): 170-173)

\section{Introduction}

Post renal transplant erythrocytosis (PTE) is defined as persistently elevated haemoglobin and haematocrit levels that occur following renal transplantation and persist for more than six months in the absence of thrombocytosis, leukocytosis or other potential causes of erythrocytosis. ${ }^{1}$ A haematocrit level greater than 51 percent in renal graft recipient has been generally used as a cut off value for definition of PTE. ${ }^{2}$ PTE occurs in $10-20 \%$ of the recipients of renal allografts, most often during the first 2 years following transplantation. After renal transplantation and successful engraftment, PTE has been found to develop within a period of 8 to 24

\section{Author Information}

a. Dr. Mohammad Mehfuz-E-Khoda, Junior Consultant, Dialysis and Kidney Transplant Unit, BIRDEM General Hospital, Dhaka, Bangladesh

b. Dr. Ishrat Jahan Shimu, Assistant Registrar, Department of Cardiology, National Institute of Cardiovascular Disease, Dhaka, Bangladesh

c. Dr. Md. Golzar Hossain, SMO \& Transplant Coordinator, Dialysis and Transplant Unit, BIRDEM General Hospital, Dhaka, Bangladesh

d. Dr. Mirza Shariful Haque and Dr. Moontasim Akhter Moon, SMO, Dialysis Unit, BIRDEM General Hospital, Dhaka, Bangladesh

e. Dr. Muhammad Abdur Rahim, Associate Professor, Department of Nephrology, BIRDEM General Hospital, Dhaka, Bangladesh

f. Prof. Dr. Md. Abul Mansur, Professor and Director, Kidney Transplant Unit, BADAS, Dhaka, Bangladesh

Address of Correspondence: Dr. Mohammad Mehfuz-E-Khoda, MD (Internal Medicine), Junior Consultant, Dialysis and Kidney Transplant Unit, BIRDEM General Hospital, Dhaka, Bangladesh, Email:mehfuzek@yahoo.com

Received: November 24, 2018 months. ${ }^{2}$ Predisposing factors include male gender, presence of native kidney, smoking, transplant renal artery stenosis, type of immunosuppressant used (more frequently in cyclosporine-treated patient), rejection free course with well-functioning renal graft and adequate erythropoiesis prior to transplantation. ${ }^{2-5}$ Thromboembolic accidents were reported in 10-30\% cases of these of PTE patients, which may lead to death in $1-2 \%$ of them. ${ }^{2,4,5}$ Considering the relatively high incidence of PTE and its potential fatal outcome, the early diagnosis and treatment would play an important role in preventing those complications.

\section{Case Report}

A 35-year-old non-smoker and non-diabetic police officer, a live related kidney transplant recipient, presented during his regular follow-up with high level of haemoglobin with haematocrit. He is a known case of hypertension for seven years and chronic kidney disease for one and half years. He was on maintenance haemodialysis for 6 months. His transplantation was done on January, 2018. Donor was his spouse. His preand post-operative period was uneventful. He received basiliximab and methyl prednisolone as induction therapy. His maintenance immunosuppressive regime consisted of prednisolone, tacrolimus and mycophenolet mofetil. His daily urine output was around 4-5 liters per day with normal renal function (serum creatinine level in between 0.8 to $1.21 \mathrm{mg} / \mathrm{dl}$ ).

On his routine follow-up after 6 months, he was asymptomatic with normal urine output (2.5-3 lt/day) and found to have high haemoglobin levels which was 


\begin{tabular}{|c|c|c|c|c|c|c|}
\hline Date & $\begin{array}{c}\mathrm{Hb} \\
(\mathrm{gm} / \mathrm{dl})\end{array}$ & $\begin{array}{l}\text { PCV } \\
(\%)\end{array}$ & $\begin{array}{l}\mathrm{TC} \text { of } \\
\mathrm{WBC} \\
(/ \mathrm{cmm})\end{array}$ & $\begin{array}{c}\text { Platelet } \\
\text { count } \\
(/ \mathrm{cmm})\end{array}$ & $\begin{array}{l}\text { Urea } \\
(\mathrm{mg} / \mathrm{dl})\end{array}$ & $\begin{array}{c}\text { Creatinine } \\
(\mathrm{mg} / \mathrm{dl})\end{array}$ \\
\hline (Pre-transplant) 14/1/2018 & 7.0 & 20.8 & 5400 & 100000 & 73 & 5.5 \\
\hline (Post-transplant) 21/1/2018 & 8.0 & 23.6 & 7580 & 128000 & 45 & 2.7 \\
\hline (During discharged) 29/01/2018 & 9.7 & 28.9 & 8430 & 302000 & 32 & 0.8 \\
\hline ( $1^{\text {st }}$ follow-up) $2 / 2 / 2018$ & 13.3 & 30.2 & 14070 & 394000 & 32 & 1.1 \\
\hline (2nd follow-up) 4/3/2018 & 12.4 & 29.6 & 9040 & 276000 & 28 & 1.0 \\
\hline (5 $5^{\text {th }}$ follow-up) $8 / 7 / 2018$ & 15.7 & 52 & 12370 & 232000 & 34 & 1.2 \\
\hline (6 $6^{\text {th }}$ follow-up) $9 / 9 / 2018$ & 18.1 & 54.6 & 8600 & 306000 & 35 & 1.1 \\
\hline ( $7^{\text {th }}$ follow-up) $6 / 10 / 2018$ & 19.4 & 58.9 & 7950 & 221000 & 27 & 1.0 \\
\hline ( $8^{\text {th }}$ follow-up) $7 / 11 / 2018$ & 18.5 & 56 & 9060 & 211000 & 21 & 09 \\
\hline
\end{tabular}

persistent. He had no history of headache, dizziness, epistaxis, blurred vision, diarrhea, vomiting or polyuria and he was not on any diuretic medication prior to this episode. His blood pressure was within normal limits with antihypertensive medication (amlodipine and prazosin).

Investigation reports showed haemoglobin $18.1 \mathrm{gm} / \mathrm{dl}$, haematocrit 56\%, mean corpuscular volume $85.2 \mathrm{ft}$, mean corpuscular haemoglobin $28.2 \mathrm{pg}$, mean corpuscular haemoglobin concentration $33.0 \mathrm{~g} / \mathrm{dl}$, total white cell count $8.60 \times 10^{9} / 1$, platelet count $306 \times 10^{9} / 1$, random blood glucose $5.4 \mathrm{mmol} / \mathrm{l}$, normal liver biochemistry, urea $30 \mathrm{mg} / \mathrm{dl}$, creatinine $1.1 \mathrm{mg} / \mathrm{dl}$, tacrolimus levels $6.0 \mathrm{ng} / \mathrm{ml}$, urine routine examinationprotein trace, pus cell 0-2/high power field (HPF), epithelial cell $0-2 / \mathrm{HPF}$, red cells 2-4/HPF, abdominal ultrasound showed normal transplanted kidney with good vascular flow up to periphery and resistivity index (RI) was $<1$. His haemoglobin level was persistently raised (in between 18.4-19.4 $\mathrm{gm} / \mathrm{dl}$ ) with raised haematocrit (in between 56-58.9\%) for three consecutive visits within previous 3 months (Table I).

Despite of his high haemoglobin and haematocrit, he remained asymptomatic. He was advised for regular follow-up and report if headache and dizziness occurs.

\section{Discussion}

Erythrocytosis following renal transplantation has been recognized since $1965,5,6$ The published prevalence of
PTE in kidney transplant recipient ranges from 6.5 to $38.4 \% .{ }^{7}$ The threshold haematocrit used to define PTE is variable and ranges between 51-54 percent; most clinician use 51 percent (corresponding to haemoglobin concentration of approximately $17 \mathrm{gm} / \mathrm{dl}$ ). ${ }^{2}$ The incidence of PTE appears to be decreasing. Erythrocytosis defined as haemoglobin $>17 \mathrm{gm} / \mathrm{dl}$ was reported in 19 percent of those transplanted between 1993 to 1996 , but only 8 percent of those transplanted between 1997 to $2005 .^{8}$

Almost all cases of PTE develop in transplant recipients who have retained native kidneys. ${ }^{4,}{ }^{10}$ Patients with polycystic kidney disease (PKD) and glomerulonephritis were more likely to develop PTE in some studies. ${ }^{11}$ Renal artery stenosis of the native or transplanted kidney was suggested as a risk factor for PTE in early case reports. ${ }^{2,5}$

The pathogenesis of PTE is multifactorial and not well understood. The following hormonal systems and growth factors have been implicated in the pathogenesis of PTE: erythropoietin, hematopoietic growth factors such as insulin-like growth factor-1 (IGF-1) and its binding proteins and serum-soluble stem cell factor (sSCF), renin-angiotensin system (RAS) and endogenous androgens.

PTE usually occurs 8 to 24 months after transplantation. ${ }^{2}$ In the absence of treatment, PTE spontaneously remits in one-fourth of patients within two years from onset. In the remainder of patients, PTE persists for a number 
of years, after which it may remit in association with deteriorating renal function due to chronic rejection. ${ }^{12}$ Approximately 60 percent of patients with PTE experience malaise, headache, plethora, lethargy and dizziness; 10 to 30 percent develop thromboembolic events; and 1 to 2 percent eventually die of associated complications if untreated and if erythrocytosis does not spontaneously remit. Thromboembolic events may involve both veins and arteries and are manifested as thrombosis of digital or branchial arteries, thrombophlebitis, stroke or pulmonary embolus. ${ }^{13}$ Platelet and leukocyte counts are normal and arterial blood gases are normal in patients with PTE. ${ }^{2}$

The diagnosis of PTE is made by clinical feature and laboratory finding and by the exclusion of common causes of nontransplant-associated erythrocytosis, including malignancies and in selected patients, chronic obstructive pulmonary disease (COPD). An ultrasound with Doppler waveform analysis of renal arteries of the native and transplanted kidneys and assessment of cytology of three morning urine samples in order to exclude renal artery stenosis and an underlying renal carcinoma respectively are useful. The measurement of erythropoietin concentrations is not helpful among transplant recipients, since high and low concentrations have been demonstrated among PTE patients. Measurement of renin-angiotensin system (RAS) activity, goralatide or insulin-like growth factor-1 (IGF1) concentrations are also not helpful in making the diagnosis or direct treatment and are not performed among transplant recipients.

The preferred initial treatment for patients with PTE who have a hemoglobin concentration $<18.5 \mathrm{~g} / \mathrm{dL}$ is an angiotensin receptor blocker (ARB) or angiotensinconverting enzyme (ACE) inhibitor since these agents are effective in the majority of patients, are reasonably safe and among many patients, provide a necessary antihypertensive effect.

Patients who present with hemoglobin concentration $>18.5 \mathrm{~g} / \mathrm{dL}$ are generally treated with phlebotomy, along with the ARB or ACE inhibitor. Patients in whom an $A R B$ or ACE inhibitor is ineffective in reducing the hemoglobin concentration are treated with serial phlebotomy. Although theophylline has been shown to be effective in treating PTE, it is rarely used, except in selected patients, because of the requirement for monitoring serum concentrations and because of undesirable side effects including tremor and insomnia. Similarly antiproliferative agents such as azathioprine or mammalian (mechanistic) target of rapamycin (mTOR) inhibitors may decrease erythrocytosis, but altering the immunosuppressive regimen to include such agents is not commonly done in the absence of other indications. The optimal haemoglobin among patients with PTE is not known. A target haemoglobin level $<17.5 \mathrm{~g} / \mathrm{dL}$ and continued therapy for PTE indefinitely since relapse of erythrocytosis is common and since the majority of renal transplant recipients are hypertensive and these drugs may slow the rate of progressive renal dysfunction. ${ }^{14}$ Relapse of erythrocytosis is common if treatment is discontinued. ${ }^{14}$

\section{Conclusion}

PTE should be borne in mind when kidney transplant recipients present with high haemoglobin and haematocrit levels. Early diagnosis and appropriate actions may reduce the complication and fatal outcome of PTE.

Conflict of interest: Nothing to declare.

\section{References}

1. Gaston RS, Julian BA, Curtis JJ. Post-transplant erythrocytosis: an enigma revisited. Am J Kidney Dis 1994; 24:1.

2. Vlahakos DV, Marathias KP, Agroyannis B, Madias NE. Posttransplant erythrocytosis. Kidney Int 2003; 63:1187.

3. Thevenod F, Radtke HW, Grutzmacher P, Vincent E, Koch KM, Schoeppe W, et al. Deficient feedback regulation of erythropoiesis in kidney trasant patients with polycythemia. Kidney Int 1983;24:227-32.

4. Einollahi B, Lessan-Pezeshki M, Nafar M, PouReza-Gholi F, Firouzan A, Farhangi, F et al. Erythrocytosis after renal transplantation: review of 101 cases. Transplant Proc 2005; 37:3101.

5. Wickre CG, Norman DJ, Bennion A, Barry JM, Bennet WM. Post renal transplant erythrocytosis: a review of 53 patients. Kidney Int 1983;23(5):731-37.

6. Gharamani NL, MalekHosseini, RaisJalali GA. Factors relating to posttransplant erythrocytosis in renal allograft recipients. Transplant Proc 2008; 30(2):828-29.

7. Westermann MP, Jenkins IL, Dekker A, Kreutner A, Fisher B. Significance of erythrocytosis and increased erythropoeitin secretion after renal transplantation. Lancet 1969;2:755-57. 
8. Kiberd BA. Post-transplant erythrocytosis: a disappearing phenomenon? Clin Transplant 2009; 23:800.

9. Qunibi WY, Barri Y, Devol E, Al-Furayh O, Sheth K, Taher S. Factors predictive of post-transplant erythrocytosis. Kidney Int 1991;40:1153-59.

10. Dagher FJ, Ramos E, Erslev A, Karmi S, Alongi SV. Erythrocytosis after renal allotransplantation: treatment by removal of the native kidneys. South Med J 1980; 73:940.

11. Razeghi E, Kaboli A, Pezeshki ML, Meysamie AP, Khatami MR, Khashayar P. Risk factors of erythrocytosis post renal transplantation. Saudi J Kidney Dis Transpl 2008; 19:559.
12. Kessler M, Hestin D, Mayeux D, Mertes PM, Renoult E. Factors predisposing to post-renal transplant erythrocytosis. A prospective matched-pair control study. Clin Nephrol 1996; 45:83.

13. Perazella M, McPhedran P, Kliger A, Lorber M, Levy E, Bia MJ. Enalapril treatment of posttransplant erythrocytosis: efficacy independent of circulating erythropoietin levels. Am J Kidney Dis 1995; 26:495.

14. Yildiz A, Cine N, Akkaya V, Sahin S, Ismailoglu V, Turk S, et al. Comparison of the effects of enalapril and losartan on posttransplantation erythrocytosis in renal transplant recipients: prospective randomized study. Transplantation 2001; 72:542. 